\title{
Design of an Experimental Device for Simulation of Pipeline Expansion
}

\author{
Juraj Drga ${ }^{1, *}$, Michal Holubčík ${ }^{1}$, and Stanislav Gavlas ${ }^{1}$ \\ ${ }^{1}$ University of Zilina, Department of Power Energy, Univerzitná 8215/1, 01026 Zilina, Slovakia
}

\begin{abstract}
This article describes the design of an experimental device for simulating pipe expansion. The device consisted of various variants of compensating elements and types of piping materials. Based on this, a 3D model was developed, together with numerical design calculations of compensators. Subsequently, a more complex analysis was performed by using the CAE Pipe calculation program, which performed calculations of dilatations, forces at fixed points and stresses in the pipeline.
\end{abstract}

\section{Introduction}

Thermal expansion causes stresses that can escalate to exceeding the allowable stress of the pipe material. The force that arises as the compressive force during expansion and the tensile force during shrinkage of the material, is equally stressful for the joints and supports of the pipeline network. That's the reason why is very important to compensate the thermal expansion of the pipe either by the pipe's own flexibility or by compensators [1]. In addition, the design of the pipeline network must consist of calculations of the pipe wall thickness and the allowable pipe stresses, which are complex calculations involving the effects of load conditions, operating conditions or properties of the materials used [2]. A lot of studies have already been devoted to the topic of pipeline expansion, most often dealing with the design of the pipeline network, the effects of thermal expansion on the pipeline network, examining the thermal expansion of various materials, or dilatation of the pipe to our conditions in unconventional conditions [3-5]. The essence of this article was the design of an experimental device for the simulation of pipe expansion, which will later be used as a teaching aid. The inspiration from the point of view of work processing stemmed from the principle of work processing on the use of heat pipes for heat transfer from the flue gas [6]. The designed device consisted of various types of compensators. These represented 3 types of natural compensator ("L" compensator, "Z" compensator and " $U$ " compensator) and one variant of axial bellows compensator. Natural expansion joints were designed for 3 types of materials (polyethylene, galvanized steel and copper), for the variant with an axial bellows expansion joint, galvanized steel piping was considered. The calculations in the article were divided into 2 parts for numerical calculations, based on the basic formulas for defining the dimensions of the compensating elements and their associated expansion displacements, and the calculations performed in the calculation program CAE Pipe, to obtain more accurate

\footnotetext{
${ }^{*}$ Corresponding author: juraj.drga@ $@$ fstroj.uniza.sk
} 
results of expansion displacements, forces at fixed points a stresses acting on pipeline sections. For all variants of compensators, the calculated length of the expansion section was considered to be $2 \mathrm{~m}$. No further attention was paid to a deeper analysis of the effect of stresses on the pipeline. If demands were made to investigate potential deformations of the pipeline, in the context of the design of the device, such a solution could be counterproductive, due to the complexity of the whole process and the purpose of the study [7]. The same can be said for the analysis of heat transfer by pipeline network [8]. The advantage of the CAE Pipe software was the possibility of obtaining the data in various load cases. For the needs of the design, load conditions were considered as the effect of the self-weight of the pipeline (Empty weight - W1), the effect of temperature (Expansion - T1) and the effect of weight, pressure and temperature (Operating - W1 + P1 + T1).

\section{Experimental device}

Figure 1 shows a scheme of the proposed device, which will consist of:

1. Refrigerated - Heating circulator JULABO to regulate the circulating water temperature,

2. Measuring control panel for sensing the surface temperature of the pipeline using a contact temperature sensor,

3. Computer for processing and evaluation of data from the measuring control panel,

4. Natural or axial compensators, on which the effects of thermal expansion will be simulated. These will form complex compensating sections, which will include additional elements such as a manometer, vent valve, measures for visual reading of expansion displacements, fixed points and sliding supports for fixing the expansion section on the board with the stand.

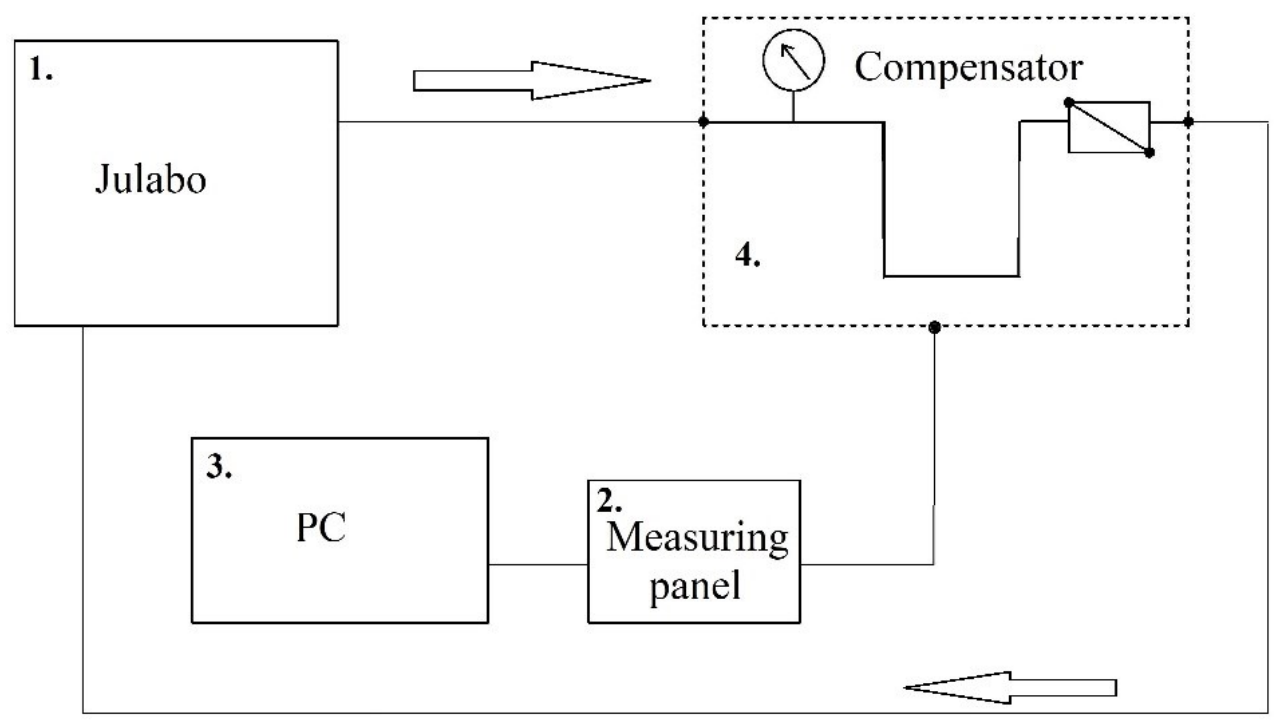

Fig. 1. Scheme of the experimental device.

Figure 2 shows a 3D model of the proposed device in a variant with a natural "U" compensator. Julabo FP35-HL is a heating circulation pump with a range of operating temperatures $-35^{\circ} \mathrm{C}$ to $+150^{\circ} \mathrm{C}$, with a heating capacity of $2 \mathrm{~kW}$. This will be connected to 
the loop of the compensating section by flexible water hoses, as an inlet and outlet of the circulating water. The measuring control panel will be used to sense the surface temperature of the pipeline through the input for the Pt 100 contact sensor. The task of venting the section will be performed by the DISCALSLIM Caleffi vent valve for horizontal pipes, with a maximum operating pressure of 5 bar and a temperature of $110^{\circ} \mathrm{C}$. The length changes in the expansion sections will be shown by a pointer located at the end of the section and the length gauge, Figure 3.

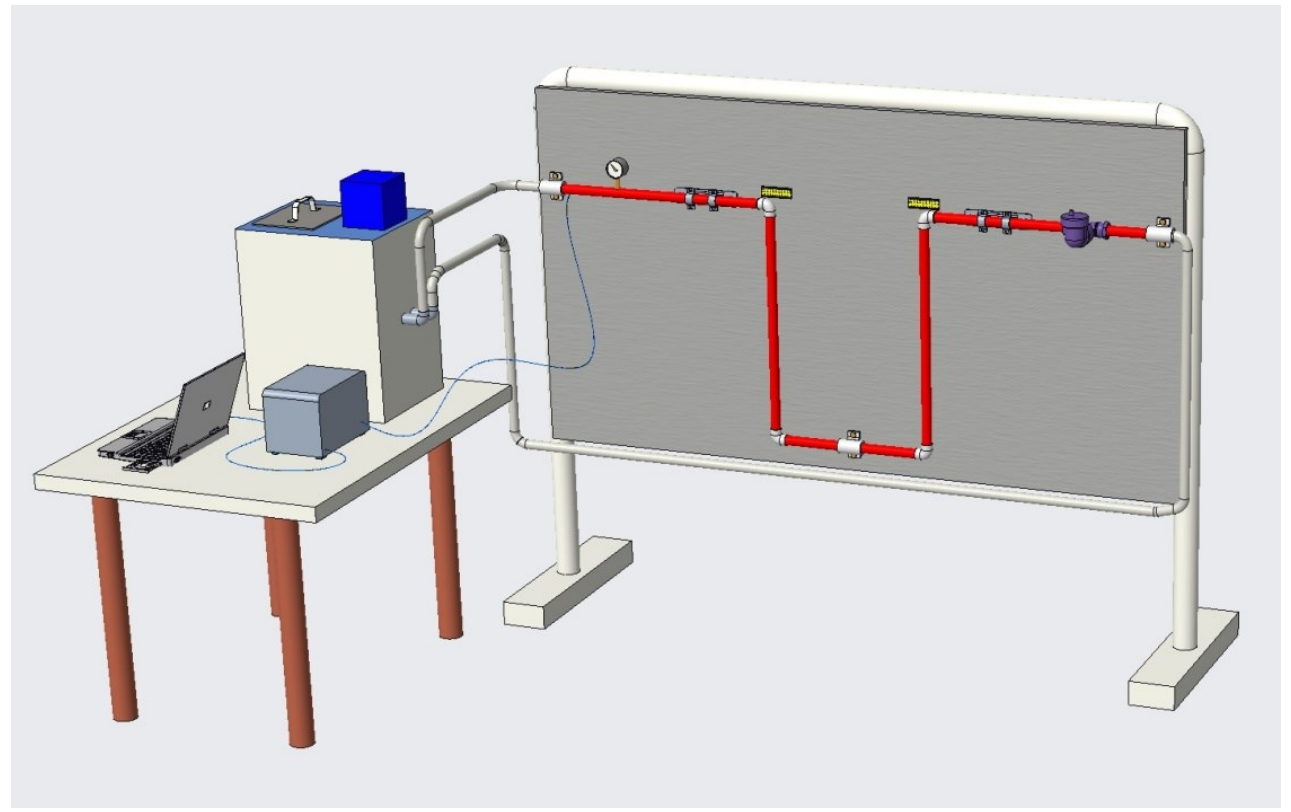

Fig. 2. 3D model of the experimental device.

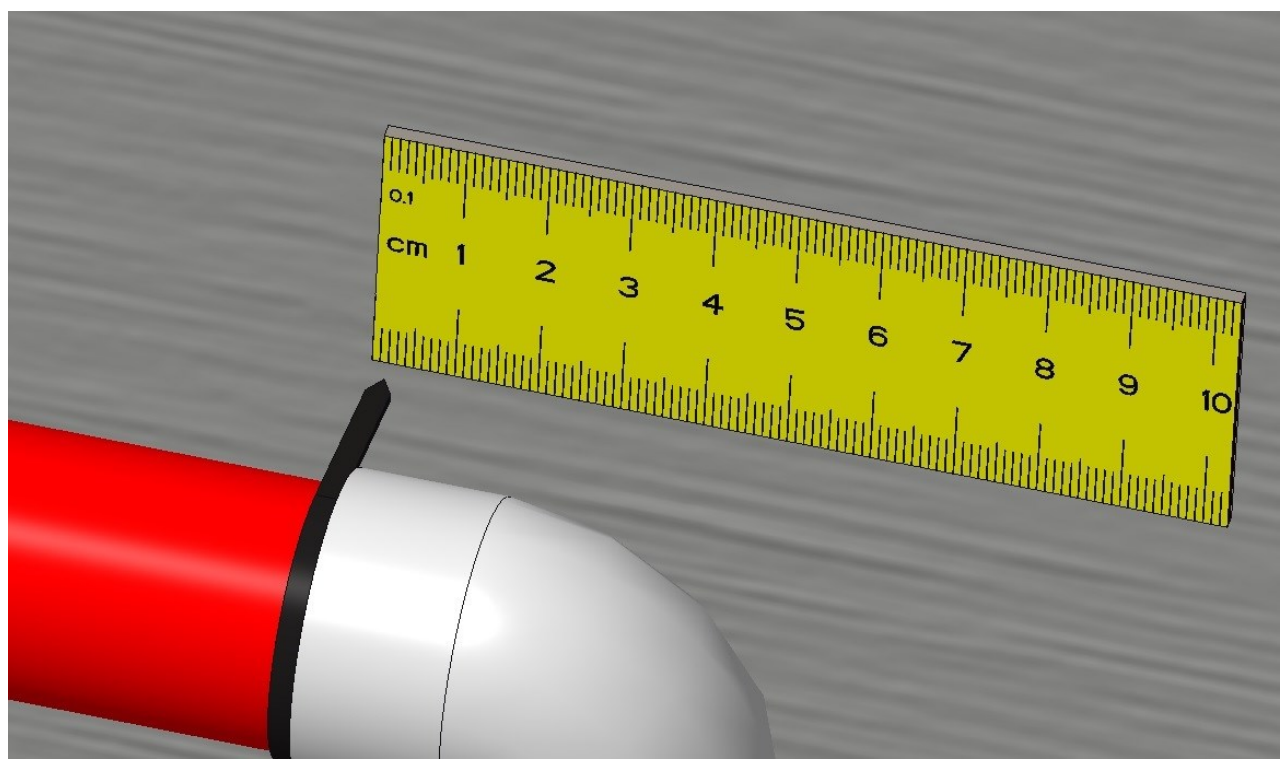

Fig. 3. Detail of the measure. 


\section{Numerical calculations}

Numerical calculations were performed as calculations of dilatations of individual materials for pipes with a length of $2 \mathrm{~m}$, together with calculations of the dimensions of natural compensators "U", "Z" and "L". The calculation of thermal expansion was based on the basic formula [9]:

$$
\Delta L=L_{0} \cdot \alpha \cdot \Delta T[\mathrm{~mm}]
$$

where $\Delta L$ is change of the length of the pipeline due thermal expansion, $L_{0}$ is the length of the pipeline section, $\alpha$ is the coefficient of thermal expansion and $\Delta T$ is the change of the temperature. The values of the coefficient of thermal expansion $\alpha$ are expressed in Table 1 .

Table 1. Coefficients of thermal expansion.

\begin{tabular}{|c|c|}
\hline Material & Coefficient of thermal expansion $\left[\mathbf{K}^{-1} \mathbf{]}\right.$ \\
\hline Steel & $1.2 \cdot 10^{-5}$ \\
\hline Cooper & $1.8 \cdot 10^{-5}$ \\
\hline PE & $18 \cdot 10^{-5}$ \\
\hline
\end{tabular}

For the purposes of this article, a variant of the "U" compensator was selected from all considered compensators, because the principle of calculations of natural compensators was identical in all selected types. For these types of expansion joints, the outer diameter of the pipe was calculated to be $D=32 \mathrm{~mm}$. The dilatation of the pipe with the length of $2 \mathrm{~m}$ was calculated by mentioned formula (1) at different temperature changes. Then during the device designs and calculations in the CAE Pipe software, the temperature change $\Delta T=50 \mathrm{~K}$ was considered. The obtained results of length expansion are shown in Table 2.

Table 2. Thermal expansion of the $2 \mathrm{~m}$ pipeline.

\begin{tabular}{|c|c|c|c|}
\hline $\begin{array}{c}\Delta \boldsymbol{L} \text { for 2m pipeline } \\
{[\mathbf{m m}]:}\end{array}$ & PE & Steel & Copper \\
\hline$\Delta T=10 \mathrm{~K}$ & 3.6 & 0.24 & 0.36 \\
\hline$\Delta T=20 \mathrm{~K}$ & 7.2 & 0.48 & 0.72 \\
\hline$\Delta T=30 \mathrm{~K}$ & 10.8 & 0.72 & 1.08 \\
\hline$\Delta T=40 \mathrm{~K}$ & 14.4 & 0.96 & 1.44 \\
\hline$\Delta T=50 \mathrm{~K}$ & 18 & 1.2 & 1.8 \\
\hline
\end{tabular}

The calculations of the dimensions of natural compensators were based on the formula for the calculation of the length of the compensating arm, at the same time the individual dimensions are explained in Figure 4 [9]:

$$
L_{l}=C \cdot \sqrt{ }(D \cdot \Delta L)[\mathrm{mm}] ; L_{U} \geq\left(L_{1} / 2\right)
$$

where $L_{l}$ is the length of the compensating arm, $C$ is the material coefficient, $D$ is the outer diameter of the pipe and $L_{U}$ is the width of the compensator.

The obtained dimensions of the compensating arm are shown in Table 3, for three types of materials at different temperature changes. The size of the compensating arm depends on the mechanical properties of the materials used as well as on the value of the coefficient of thermal expansion. The higher the value is, the greater space requirements for the construction of the natural compensator are needed, which also follows from Table 3. 
$\mathrm{L}_{0}$

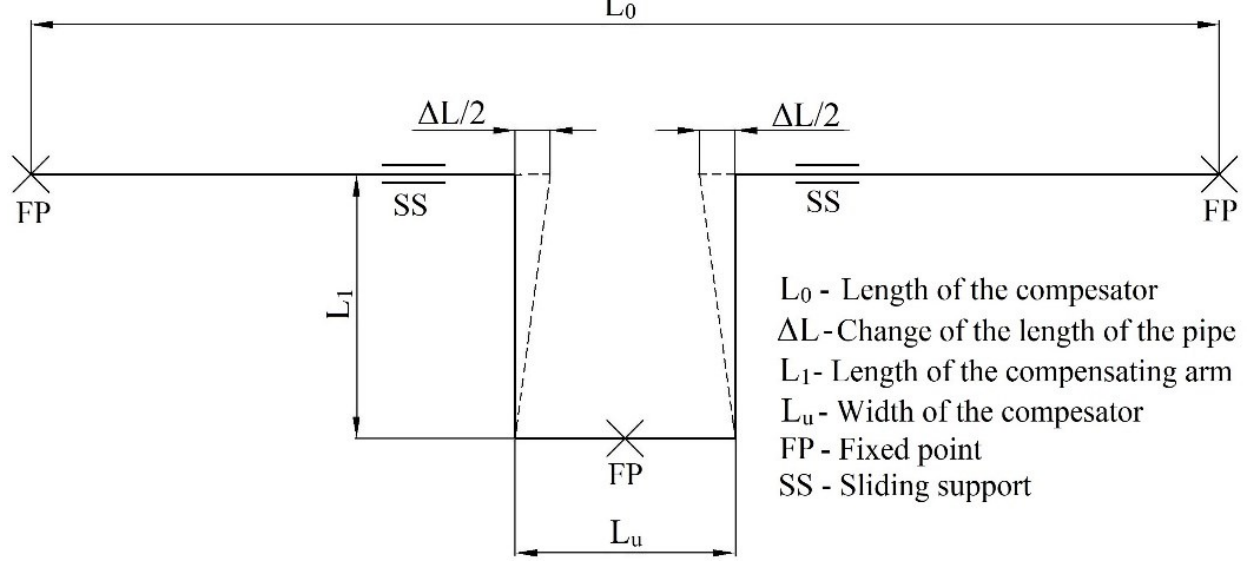

Fig. 4. Dimensions of "U" compensator.

Table 3. Dimensions of the compensating arm $L_{1}$.

\begin{tabular}{|c|c|c|c|c|c|}
\hline $\begin{array}{c}\text { Compensating arm } \boldsymbol{L}_{\boldsymbol{1}} \\
{[\mathbf{m m}]}\end{array}$ & $\boldsymbol{\Delta T}=\mathbf{1 0} \mathbf{K}$ & $\boldsymbol{\Delta T}=\mathbf{2 0} \mathbf{K}$ & $\boldsymbol{\Delta T}=\mathbf{3 0} \mathbf{K}$ & $\boldsymbol{\Delta T}=\mathbf{4 0} \mathbf{K}$ & $\boldsymbol{\Delta T}=\mathbf{5 0} \mathbf{~}$ \\
\hline PE & 290 & 410 & 502 & 580 & 648 \\
\hline Steel & 100 & 141 & 173 & 200 & 223 \\
\hline Copper & 54 & 77 & 94 & 109 & 121 \\
\hline
\end{tabular}

\section{Analysis of calculations in the CAE Pipe software}

The obtained designs of compensating elements from numerical calculations were used as models in the calculation program CAE Pipe. For the program calculations was used the software version of CAE Pipe EVAL 10.10 (free to download from: $<$ https://www.sstusa.com/piping-software-download.php $>$ ). It offered the possibility of analysis of expansion displacements of natural compensators and the magnitude of forces on fixed points, in load cases:

- Empty weight (W1) - due to the weight of the pipe,

- Expansion (T1) - due to temperature,

- $\quad$ Operating (W1 + P1 + T1) - due to weight, pressure and temperature.

In the variant of an axial compensator, the forces on the fixed points were examined together with the compression of the compensator. The effects of the compensator on the pipe section were compared with a straight pipeline with a length of $2 \mathrm{~m}$ without the compensator, guided by two fixed points. Figure 5 shows an animation of the dilatation of the "U" compensator, placed by three fixed points and two sliding supports. The analysis was based on input data and materials according to Table 4 .

The results of expansion displacements and angular deflections included the values obtained in the three planes $\mathrm{X}, \mathrm{Y}, \mathrm{Z}$, which gave the results a more realistic idea of the behaviour of the pipeline section in practice, due to different loading conditions. The individual designations of the elements of the pipe section in Figure 5 belong to the designations expressed in Table 5, which contains the maximum values of displacements in the $\mathrm{X}$ and $\mathrm{Y}$ axis [mm], and the values of angular deflections $\left[{ }^{\circ}\right]$ for PE pipe material, in the three selected load cases. 
Table 4. Input data of CAE Pipe calculations.

\begin{tabular}{|c|c|c|c|}
\hline & PE & Steel & Copper \\
\hline Material & EN 15494 & EN 1.0425 (P265GH) & EN 1057 \\
\hline Temperature & & $65^{\circ} \mathrm{C}$ & \\
\hline Pressure & & $5 \mathrm{bar}$ \\
\hline
\end{tabular}

承
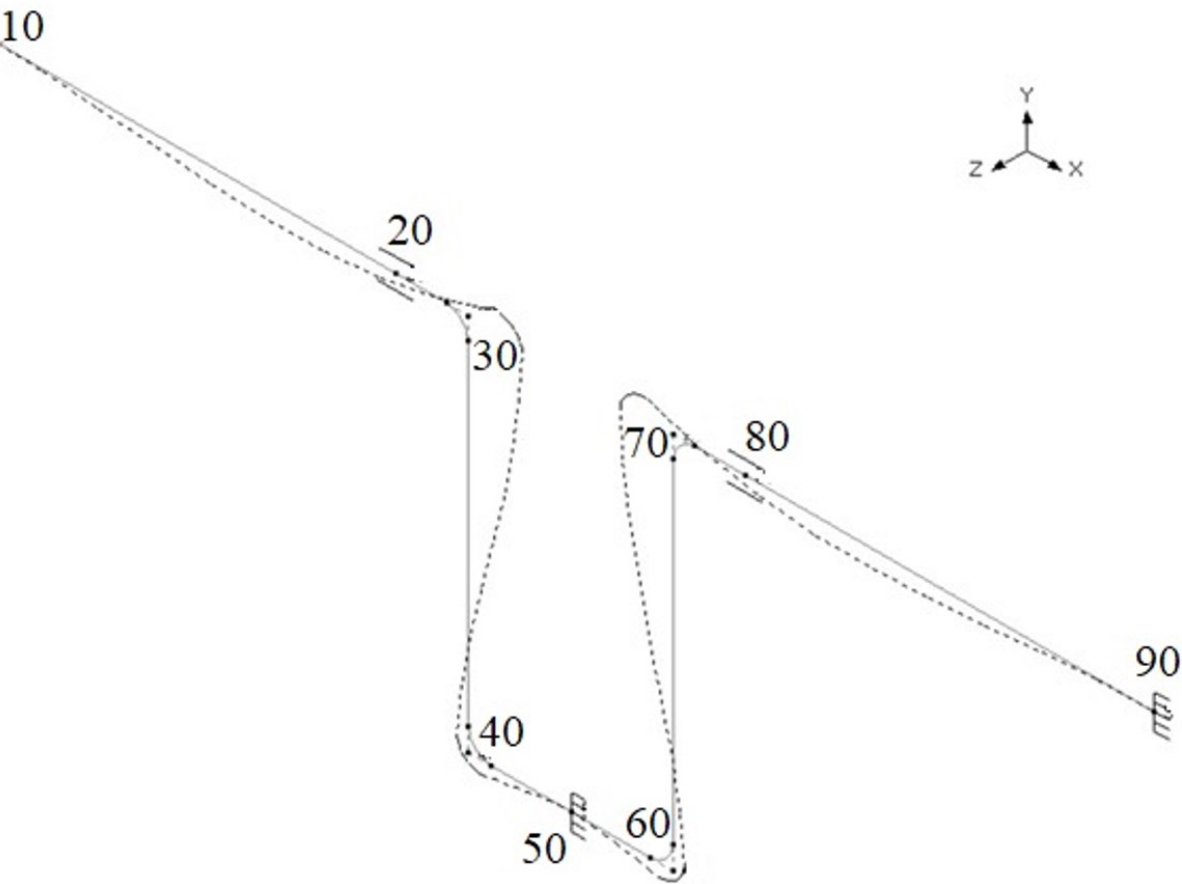

Fig. 5. Animation of the dilatation of the compensator.

Table 5. Maximum values of the displacements and angular deflections of the PE "U"compensator.

\begin{tabular}{|c|c|c|c|c|c|c|c|}
\hline \multicolumn{2}{|c|}{ PE } & \multicolumn{2}{|c|}{ Empty weight (W1) } & \multicolumn{2}{|c|}{ Expansion (T1) } & \multicolumn{2}{|c|}{$\begin{array}{c}\text { Operating } \\
\text { (W1+P1+T1) }\end{array}$} \\
\cline { 3 - 9 } & & $\#$ & Value & $\#$ & Value & $\#$ & Value \\
\hline \multirow{2}{*}{$\mathrm{X}[\mathrm{mm}]$} & Min & 30 & -0.010 & 70 & -6.890 & 70 & -6.880 \\
\cline { 2 - 8 } & Max & 70 & 0.010 & 30 & 6.890 & 30 & 6.880 \\
\hline \multirow{2}{*}{$\mathrm{Y}[\mathrm{mm}]$} & Min & 40 & -0.033 & 60 & -1.720 & 60 & -1.753 \\
\cline { 2 - 8 } & Max & 10 & 0.000 & 30 & 2.647 & 30 & 2.614 \\
\hline \multirow{2}{*}{$\mathrm{ZZ}\left[^{\circ}\right]$} & Min & 30 & -0.016 & 70 & -1.381 & 70 & -1.365 \\
\cline { 2 - 8 } & Max & 70 & 0.016 & 30 & 1.381 & 30 & 1.365 \\
\hline
\end{tabular}

Table 6 contains the resulting values of the forces at fixed points for PE material, in the operating load case. 
Table 6. Forces at fixed points in load case Operating

\begin{tabular}{|c|c|c|c|c|}
\hline & $\#$ & FX $[\mathrm{N}]$ & FY $[\mathrm{N}]$ & $\begin{array}{c}\mathrm{MZ} \\
{[\mathrm{Nm}]}\end{array}$ \\
\hline \multirow{3}{*}{$\mathrm{PE}$} & 10 & -16 & -10 & -2 \\
& 50 & 0 & -165 & 0 \\
\hline & 90 & 16 & -10 & 2 \\
\hline
\end{tabular}

The values of the obtained dilatation results by numerical calculation and calculation in the program report a deviation. This is mainly because the calculation program CAE Pipe considered with the real conditions of load cases and stresses in all directions, i.e. with axial and lateral load of the pipe section.

The distributions of stresses acting on PE pipe sections is shown in Figure 6. The highest values were shown by steel pipes and the lowest by PE pipes, due to their good elastic properties. However, the disadvantage of this type of pipe is the higher value of the coefficient of thermal expansion, which causes the associated space requirements for guiding the pipe, respectively for natural compensators.

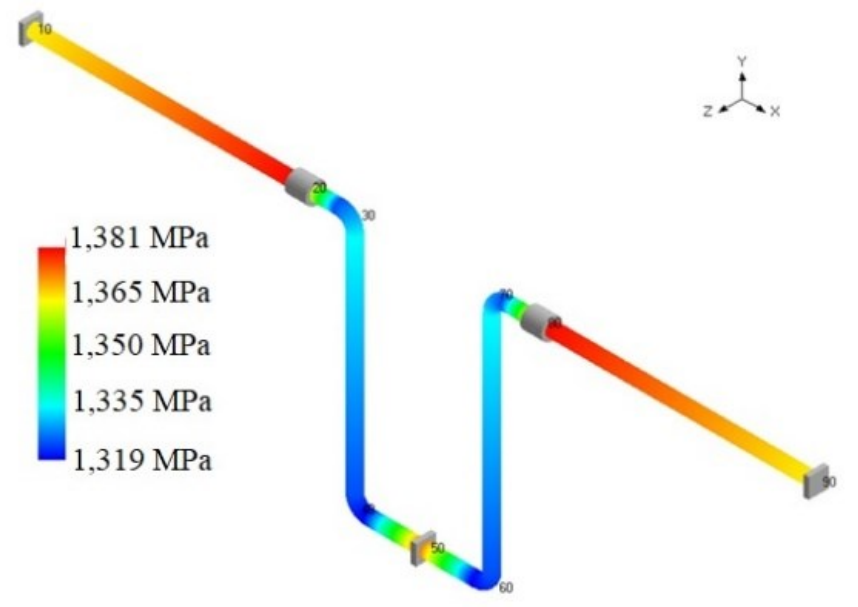

Fig. 6. Stresses acting on pipe section of PE.

\section{Conclusions}

Although the issue of pipeline expansion is clarified in practice, it can be argued that the proposed experimental device will serve its purpose as a teaching aid in academic studying [10]. Thanks to this device, students will be able to observe the effect of thermal expansion on the pipeline system and analyse its behaviour under various simulated conditions. The most suitable variant among those proposed in the work seems to be a device with natural compensators made of $\mathrm{PE}$, for a high degree of thermal expansion of the material in comparison with steel or copper. This will allow observers to see changes in the length of the pipeline to a sufficient extent. Thanks to this experience, their acquired knowledge can be further deepened and for those interested in this topic, other opportunities open up in the form of improvement in computer programs for the issue, as the CAE Pipe program used in this work. 
This work has been supported by the project KEGA 038ŽU-4/2019 "Piping systems in heat supply" and VEGA 1/0233/19 "Construction modification of the burner for combustion of solid fuels in small heat sources".

\section{References}

1. J. Neckářová, L. Doskočil, Potrubí a armatury, 137, 27 (1972)

2. P. Bhatia, A. Jha, Analytical calculation for piping thickness and stress (2014). Available from: < http://ijmcr.com/wp-content/uploads/2015/05/Paper21640-643.pdf >

3. A. Bokaian, Thermal expansion of pipe-in-pipe systems (2004). Available from: $<$ https://www.sciencedirect.com/science/article/pii/S0951833904000929>

4. T. Gerlach, M. Achmus, M. Terceros, Numerical investigation on district heating pipelines under combined axial and lateral loading (2018). Available from: $<$ https://www.sciencedirect.com/science/article/pii/S1876610218305046>

5. S. Scheiner, B. Pichler, B. Hellmich, J. Eberhardsteiner, Loading of soil-covered oil and gas pipelines due to adverse soil settlements - Protection against thermal dilatation induced wear, involving geosynthetics (2006). Available from:

$<$ https://www.sciencedirect.com/science/article/pii/S0266352X06000851>

6. R. Lenhard, K. Kaduchová, Š. Papučík, J. Jandačka. Utilization of heat pipes for transfer heat from the flue gas into the heat transfer medium, EPJ web of conferences 67, 02067 (2014)

7. M. Neslušan, L. Trško, P. Minárik, J. Čapek, J. Bronček, F. Pastorek, J. Č́ížek, J. Moravec, Non-Destructive Evaluation of Steel Surfaces after Severe Plastic Deformation via the Barkhausen Noise Technique (2018)

8. M. Vantúch, J. Hužvár, A. Kapjor, Heat transfer, 8th International Conference on Experimental Fluid Mechanics Location, Liberec (2013)

9. P. Pospíšil, Kompenzace délkových změn potrubí (2020). Available from: $<$ https://adoc.tips/kompenzace-delkovych-zmn-potrubi.html $>$

10. Z. Mingaleva, I. Klackova, A. Selezneva, N. Shaidurova, Failure Mode and Effects Analysis of the Consequences of the Life Cycle of the University Educational Services. ICETA 2019, 845, 531-535 (2019) 